\title{
Correction to: Mine Ventilation
}

\section{Correction to:}

\section{Sierra, Mine Ventilation,}

https://doi.org/10.1007/978-3-030-49803-0

The original version of the book was inadvertently published without the Introduction section of each chapter, along with misplacement of some figures and missed typographical errors across chapters, which have now been incorporated and corrected accordingly.

The updated version of the book can be found at https://doi.org/10.1007/978-3-030-49803-0

(C) The Editor(s) (if applicable) and The Author(s), under exclusive license 